\title{
HUBUNGAN PENGETAHUAN DENGAN PENANGANAN DISMENOREA PADA REMAJA PUTRI DI KOTA SEMARANG
}

\author{
Titik Kurniawati ${ }^{1)}$ Widyah Setiyowati ${ }^{2)}$ Dwi Mahardika ${ }^{3)}$ \\ 1,2,3 A kademi Kebidanan Abdi Husada Semarang \\ Email: kurniawati2233@yahoo.co.id
}

\begin{abstract}
ABSTRAK
Pendahuluan: Dari hasil penelitian di Amerika Serikat persentase kejadian dismenore sekitar $60 \%$, Swedia 72\% dan di Indonesia 55\%. Penelitian di Amerika Serikat menyebutkan bahwa dismenore dialami oleh $30-50 \%$ wanita usia reproduksi dan $10-15 \%$ diantaranya kehilangan kesempatan kerja, mengganggu kegiatan belajar di sekolah dan kehidupan keluarga, kehilangan kesempatan kerja, mengganggu kegiatan belajar di sekolah dan kehidupan keluarga. Metode: Jenis penelitian observasional dengan rancangan cross sectional, untuk melihat hubungan antara pengetahuan dan sikap tentang dismenorea dengan penanganan dismenorea pada subyek yang dilakukan bersamaan pada satu waktu, di wilayah Kelurahan Pakintelan Kecamatan Gunungpati Kota Semarang, pada bulan Mei 2019. Populasi adalah remaja putri di Kelurahan Pakintelan Kecamatan Gunungpati Kota Semarang yang mengalami dismenorea yang berjumlah 30 orang. Sampel berjumlah 30 orang, dengan tehnik sampling yaitu total sampling. Hasil: Pengetahuan remaja putri tentang Dismenorea terbanyak pada kategori cukup sebesar 18 orang $(60,0 \%)$. Penanganan dismenorea sebagian besar adalah ditangani yaitu 27 responden $(90,0 \%)$. Berdasarkan hasil pengujian didapatkan nilai $\mathrm{p}$ value sebesar $0,884(0,884>0,05)$ sehingga lebih besar dari 0,05 . Bahwa tidak ada hubungan pengetahuan tentang dismenorea dengan penanganan dismenorea pada remaja putri di Kelurahan Pakintelan, Kecamatan Gunungpati, Kota Semarang. Diharapkan Puskesmas wilayah setempat dapat memberikan informasi dan konseling tentang kesehatan reproduksi.
\end{abstract}

Kata Kunci: Pengetahuan, Penanganan, Dismenore.

\begin{abstract}
Introduction: From the $72 \%$ and in Indonesia 55\%. Research in the United States states that dysmenorrhea is experienced by results of research in the United States the percentage of dysmenorrhea incidence is around 60\%, Sweden 30-50\% of women of reproductive age and 10-15\% of them lose work opportunities, interfere with learning activities at school andfamily life, lose work opportunities, interfere with learning activities at school and family life. Method: This type of observational study with cross sectional design, to see the relationship between knowledge and attitudes about dysmenorrhoea with handling dysmenorrhoea on subjects carried out simultaneously at one time, in the area of Pakintelan Village, Gunungpati District, Semarang City, in May 2019. The population is young women in Pakintelan Village, Gunungpati Subdistrict, Semarang City, which experienced dysmenorrhea, amounting to 30 people. Samples amounted to 30 people, with a sampling technique that is total sampling. Results: Most of the knowledge of young women about dysmenorrhoea in the category of 18 people (60.0\%). Handling of dysmenorrhoea is mostly handled by 27 respondents (90.0\%). Based on the test results obtained p value of $0.884(0.884>0.05)$ so that it is greater than 0.05. That there is no relationship of knowledge about dysmenorrhoea with the handling of dysmenorrhoea in young women in Pakintelan Village, Gunungpati District, Semarang City. It is expected that the local health center can provide information and counseling about reproductive health.
\end{abstract}

Keywords: Knowledge, Handling, Dysmenorrhea

\section{PENDAHULUAN}

Dari hasil penelitian di Amerika Serikat persentase kejadian dismenore sekitar 60\%, Swedia $72 \%$ dan di Indonesia $55 \%$. Penelitian di Amerika Serikat menyebutkan bahwa dismenore dialami oleh $30-50 \%$ wanita usia reproduksi dan $10-15 \%$ diantaranya kehilangan kesempatan kerja, mengganggu kegiatan belajar di sekolah dan kehidupan keluarga, kehilangan kesempatan kerja, mengganggu kegiatan belajar di sekolah dan kehidupan keluarga (Paramita, 2010). Insiden dismenorea lebih banyak ditemukan pada wanita yang tingkat stress tinggi dan sedang, 
dibandingkan wanita dengan tingkat stress rendah. Risiko mengalami dismenorea meningkat hingga 10 kali pada wanita riwayat dismenorea dan stress tinggi dibandingkan wanita yang tanpa riwayat dismenorea. Faktor internal yang terpenting adalah koping individu, pendidikan dan kognitif, umur, kepribadian, intelegensi, nilai kepercayaan, budaya dan emosi. Pengetahuan yang lebih baik akan lebih membantu remaja dalam koping akibat nyeri dismenorea sehingga kualitas hidup akan lebih baik (Hartati, 2014). Kejadian dismenorea masih cukup tinggi namun masih sedikit remaja putri yang mencari informasi mengenai masalah yang timbul saat menstruasi dan dampaknya. Adanya kepercayaan dan budaya tabu membicarakan tentang menstruasi juga menghambat remaja untuk mencari informasi mengenai menstruasi dan permasalahannya khususnya tentang dismenorea. Informasi tentang menstruasi dan permasalahannya penting dalam perkembangan pelayanan kesehatan bagi remaja (Lestari, 2012). Berdasarkan latar belakang dirumuskan masalah penelitian apakah ada hubungan antara pengetahuan dengan penanganan dismenorea pada remaja putri di kelurahan Pakintelan?

\section{METODE}

Jenis penelitian observasional dengan rancangan cross sectional, untuk melihat hubungan antara pengetahuan dan sikap tentang dismenorea dengan penanganan dismenorea pada kelompok subyek yang dilakukan bersamaan pada satu waktu. Penelitian di wilayah Kelurahan Pakintelan Kecamatan Gunungpati Kota Semarang, pada bulan Mei 2019. Populasi penelitian adalah remaja putri di Kelurahan Pakintelan Kecamatan Gunungpati

Kota Semarang yang mengalami dismenorea yang berjumlah 30 orang. Sampel berjumlah 30 orang. Teknik pengambilan sampel dengan total sampling. Variabel terikat (dependent) yaitu penanganan dismenorea.Variabel bebas (independent) yaitu pengetahuan tentang dismenorea. Definisi Operasional Pengetahuan tentang dismenorea adalah kemampuan responden menjawab dengan benar pertanyaan yang terdapat dalam kuesioner penelitian berkaitan dengan dismenorea. Skala ukur adalah ordinal. Penanganan dismenorea adalah tindakan yang dilakukan responden dalam menangani keluhan yang timbul akibat nyeri haid (dismenore) fisiologis. Jenis data primer dan sekunder. Pengelolaan Data Editing, Coding, Scoring, Tabulating. Analisis Data Analisis Univariabel, Analisis Bivariat.

\section{HASIL}

1.Analisis Univariat

a. Pengetahuan Remaja

Tabel 1. Pengetahuan Dismenorea

\begin{tabular}{|c|c|c|}
\hline \multirow{2}{*}{\multicolumn{3}{|c|}{ Baik }} \\
\hline & & \\
\hline & 10 & 13.9 \\
\hline \multicolumn{3}{|l|}{ Cukup } \\
\hline & 18 & 63.9 \\
\hline \multicolumn{3}{|l|}{ Kurang } \\
\hline & 2 & 22.2 \\
\hline \multicolumn{3}{|l|}{ Total } \\
\hline & 30 & 100.0 \\
\hline
\end{tabular}

pengetahuan remaja putri tentang

Dismenorea terbanyak pada kategori b. PenangananDismenorea.

Tabel 2. Penanganan Dismenorea

\begin{tabular}{ccc}
\hline Penanganan & f & $\%$ \\
\hline Ya & 27 & 90,0 \\
\hline Tidak & 3 & 10,0 \\
\hline Total & 30 & 100.0 \\
\hline
\end{tabular}


Berdasarkan tabel di atas
menunjukan bahwa penanganan dismenorea sebagian besar adalah ditangani yaitu 27 responden $(90,0 \%)$.
Hubungan pengetahuan remaja putri tentang dismenorea dengan penanganan dismenorea di Kelurahan Pakintelan, Kecamatan Gunungpati, Kota Semarang adalah sebagai berikut:

\section{Analisis Bivariat}

Tabel 3

Hasil tabulasi silang Hubungan pengetahuan remaja putri tentang dismenorea dengan penanganan dis me norea.

\begin{tabular}{l|c|c|c|c|c|c}
\hline \multirow{2}{*}{ Pengetahuan } & \multicolumn{6}{c}{ Penanganan } \\
\cline { 2 - 7 } & \multicolumn{2}{|c|}{ Ditangani } & \multicolumn{2}{c}{ Tidak Ditangani } & \multicolumn{2}{c}{ Total } \\
\cline { 2 - 7 } Baik & $\mathrm{f}$ & $\%$ & $\mathrm{f}$ & $\%$ & $\mathrm{f}$ & $\%$ \\
\hline Cukup & 9 & 30,0 & 1 & 3,3 & 10 & 33,3 \\
Kurang & 16 & 53,3 & 2 & 6,7 & 18 & 60,0 \\
\hline Total & 2 & 6,7 & 0 & 0,0 & 2 & 6,7 \\
\hline
\end{tabular}

Berdasarkan tabel di atas dari remaja putri yang memiliki pengetahuan baik sebesar 9 (90,0\%), lebih banyak dari pada yang tidak melakukan penanganan yaitu sebanyak 1 responden $(10,0 \%)$. Kemudian tingkat pengetahuan remaja putri cukup dengan sebanyak 16 responden $(88,9 \%)$ lebih banyak dari pada yang tidak melakukan penanganan yaitu sebanyak 2 responden $(11,1 \%)$, sedangkan tingkat pengetahuan remaja putri pada kategori kurang dengan yang melakukan penanganan sebanyak 2 responden $(100,0 \%)$ dan yang tidak melakukan penanganan 0 responden $(0,0 \%)$. Berdasarkan hasil pengujian dengan Spss For Window Versi 16.00 didapatkan nilai $p$ value sebesar $0,884(0,884>$ $0,05)$ sehingga lebih besar dari 0,05 . Hal ini berati Ho diterima dan Ha ditolak, maka dapat simpulkan bahwa tidak ada hubungan pengetahuan tentang dismenorea dengan penanganan dismenorea pada remaja putri di kelurahan Pakintelan, kecamatan Gunungpati, Kota Semarang.

\section{PEMBAHASAN}

1. Pengetahuan remaja tentang Dismenorea di kelurahan Pakintelan, kecamatan Gunungpati, Kota Semarang.

Dari hasil penelitian yang telah dilakukan pada 30 responden remaja putri di kelurahan Pakintelan, kecamatan Gunungpati, Kota
Semarang, menunjukkan remaja yang memiliki pengetahuan cukup sebanyak $18 \quad(60,0 \%)$ remaja putri. Hal ini memberikan gambaran bahwa remaja putri belum cukup banyak yang mengetahui dismenorea secara baik. Dengan demikian masih perlu ditingkatkan lagi pengetahuan mereka. Sehingga sesuai dengan pendapat Widyastuti (2009) pembekalan pengetahuan tentang perubahan yang terjadi secara fisik, kejiwaan dan kematangan seksual akan memudahkan remaja untuk memahami serta mengatasi berbagai keadaan yang membingungkannya. Informasi tentang haid dan mimpi basah, serta tentang alat reproduksi lakilaki dan wanita perlu diperoleh setiap remaja. Menurut pendapat Notoatmodjo (2007), pengetahuan merupakan hasil " tahu " dan ini terjadi setelah orang melakukan penginderaan terhadap suatu objek tertentu. Sehingga perlu adanya informasi yang jelas dan sering dalam rangka agar adanya sikap yang tepat pada saat dismenorea. Pengetahuan tentang dismenorea remaja putri di kelurahan Pakintelan, kecamatan Gunungpati, Kota Semarang didapatkan pada pelajaran biologi tetapi hanya tentang menstruasi saja yang dibahas. Hasil penelitian ini menunjukkan bahwa pengetahuan dismenorea pada remaja putri di kelurahan Pakintelan, kecamatan Gunungpati, Kota Semarang.memiliki pengetahuan cukup namun masih ada remaja 
putri yang memiliki pengetahuan kurang.

2. Penanganan dismenorea pada remaja putri di kelurahan Pakintelan, kecamatan Gunungpati, Kota Semarang.

Penanganan dismenorea pada remaja putri dalam penelitian ini termasuk dalam kategori ada penanganan yaitu sebanyak 27 responden $(90,0 \%)$ dan yang tidak melakukan penanganan dismenorea sebanyak 3 responden $(10,0 \%)$. Remaja yang telah memperoleh informasi tentang dismenorea, sebagian besar memperoleh informasi dari media cetak dan elektronik dan juga dari orang tua, sumber informasi dapat menstimulus otak sehingga dapat mengingat karena dengan semakin banyak mendapat informasi maka semakin besar informasi yang diperoleh. Sumber informasi dapat diperokh darikeluarga (terutama orang tua), media cetak (surat kabar, leaflet, poster), media elektronik (televisi, radio, video), dan sumber informasi hinnya. Sariyati (2015).

3. Hubungan Pengetahuan Dismenorea Dengan Penanganan Dismenorea Pada Remaja Putri Di Kelurahan Pakintelan.

Hasil penelitian ini menunjukkan bahwa tidak ada hubungan antara hubungan pengetahuan dismenorea dengan Penanganan dismenorea pada remaja putri di Kelurahan Pakintelan, Kecamatan Gunungpati, Kota Semarang.

Remaja yang memiliki pengetahuan yang kurang akan cenderung mengabaikan kesehatan dan pada akhirnya akan memiliki tindakan yang akan membahayakan bagi dirinya sendiri. Remaja yang memiliki pengetahuan kurang tentang dismenorea akan memilih perilaku yang kurang tepat untuk menangani gangguan menstruasi berupa dismenorea tersebut (Indriastuti,2014). Pengalaman juga mempengaruhi pengetahuan seseorang, sesuatu yang pernah diami seseorang akan menambah pengetahuan orang tersebut dan dapat menjadi sumber pengetahuan yang bersifat informal Selain itu pekerjaan yang berhubungan dengan sosial ekonomi seseorang juga berpengaruh terhadap pengetahuan misalnya ekonomi menengah keatas maka akan dengan mudah memperoleh informasi dibanding dengan yang tingkat ekonominya rendah. Budaya yang ada dalam keluarga dan masyarakat juga dapat mempengaruhi tingkat pengetahuan seseorang. (Sulistina,2014).

\section{SIMPULAN DAN SARAN Simpulan}

Sebagian besar pengetahuan remaja putri tentang dismenorea di Kelurahan Pakintelan, Kecamatan Gunungpati, Kota Semarang dari 30 responden termasuk kategori cukup yaitu sebanyak 18 responden $(60,0 \%)$. Penanganan dismenorea remaja putri di Kelurahan Pakintelan, Kecamatan Gunungpati, Kota Semarang dari 30 responden termasuk kategori ada upaya yaitu sebanyak 27 responden (90.0\%). Tidak ada hubungan antara pengetahuan dismenorea dengan penanganan dismenorea pada remaja putri di Kelurahan Pakintelan, Kecamatan Gunungpati, Kota Semarang.

\section{Saran}

Bagi Puskesmas setempat dapat meningkatkan dalam memberikan informasi dan konseling melalui pelaksanaan program kegiatan bimbingan dan pembinaan tentang kesehatan reproduksi.

\section{DAFTAR PUSTAKA}

1. Abin, Syamsudin Makmum. 2003. Psikologi Pendidikan. PT Rosda Karya Remaja.Bandung

2. Alimul, A. 2007. Metode Penelitian Kebidanan dan Teknik Analisis Data. Salemba. Jakarta

3. Arikunto, S. 2006. Prosedur Penelitian suatu Pendekatan Praktek. Rineka Cipta. Jakarta

4. Azwar, A. 2003. Metodologi Penelitian. Yogjakarta: Pustaka Pelajar

5. Baron R. 2004. Psikologi Sosial jilid satu: Erlangga. Jakarta

6. Benson R. 2008. Buku saku Obstetri dan Ginekologi.:EGC Jakarta

7. Carey, C. S. 2006. Obstetri dan Ginekologi.: Widya Medika. Jakarta

8. Dinas Kesehatan Kota Semarang. 2014. Kasus PTM di Puskesmas Menurut Jenis Kelamin

9. Hartati. 2012. Mekanisme Koping Mahasiswi Keperawatan dalam Menghadapi Dismenore. Jurnal 
Ilmiah Kesehatan Keperawatan, Volume 8 No. 1 Februari.: Poltekkes Semarang. Semarang

10. Hestiantoro, dkk. 2012. Best practices on imperial (infertility, menopause, pcos, endometriosis, recurrent miscarriage, invitro fertilization, adolescent gynecology, luterine bleeding.: Sagung Seto. Jakarta

11. Hurlock, E.B. 2007. Psikologi Perkembangan Suatu Pendekatan Sepanjang Rentang Kehidupan. Erlangga. Jakarta:

12. Indriastuti. 2009. Hubungan antara Pengetahuan Kesehatan Reproduksi dengan Perilaku Higienis Remaja Putri Pada saat Menstruasi. Fakultas Psikologi Universitas Muhammadiyah Surakarta. Surakarta.

13. Jacoeb. 2006. Dismenorea aspek patofisiologi dan penatalaksanaan. Subbagian Endokrinologi Reproduksi bagian Obstetri dan Ginekologi Fakultas Kedokteran Universitas Indonesia. Jakarta.

14. Notoatmodjo, S. 2002. Pendidikan dan Perilaku Kesehatan. Rineka Cipta. Jakarta

15. Wijayanti, Daru. 2009. Fakta Penting Seputar Kesehatan Reproduksi Wanita. Book Marks. Jogjakarta 